\title{
A educação e 0 ensino de Geografia: na era da informação ou do conhecimento?
}

\section{Education and the teaching of Geography: information or knowledge age?}

\author{
José Eustáquio de Sene*
}

\begin{abstract}
Resumo: O mundo contemporâneo, especialmente a partir do último quartel do século XX, vem passando por rápidas transformações - econômicas, sociais, culturais - como resultado da mais recente revolução tecnológica. Essas mudanças tecnológicas vêm delineando o que, dependendo do autor, tem sido caracterizado como era informacional, da informação ou do conhecimento. Castells (1999), por exemplo, afirma que vivemos sob o modo de desenvolvimento informacional. Para analisar a mudança do papel do conhecimento ao longo da história, lança mão da categoria modo de desenvolvimento, que será considerada neste ensaio. Muitas vezes, esses conceitos são utilizados sem muita precisão, dificultando a compreensão da realidade. Qual é o mais apropriado para apreender o momento em que vivemos? Este artigo busca analisá-los criticamente e situar o papel da educação nesse contexto. A escola tem conseguido dar respostas às demandas de um mundo em transformação? A profusão de reformas curriculares que vem sendo implantada em diversos países é um indício de que não, de que a educação escolar ainda não encontrou um caminho consistente. Além disso, a educação não pode se restringir a dar respostas às demandas do sistema produtivo, antes de tudo deve estar voltada para a emancipação humana. E a geografia, tem conseguido adaptar-se às transformações do mundo contemporâneo e, ao mesmo tempo, explicá-lo adequadamente? O texto também levanta algumas questões acerca do papel da geografia - acadêmica e escolar - nesse contexto, embora sem aprofundá-las, o que exigiria outro artigo.
\end{abstract}

Palavras-chave: Era informacional. Mudanças na educação. Ensino de Geografia.

Abstract: The contemporary world, especially after the last quarter of the $20^{\text {th }}$ century, has been going through fast economical, social and cultural changes as a result of the recent technological revolution. According to different authors, these technological changes have characterized the information age or knowledge age. Castells (1999), for example, affirms that we live under the development information model. In order to analyze the change in the role of knowledge throughout history, he refers to a category called development mode, which is discussed in this article. These concepts are used in some cases without much precision making it difficult to understand reality. Which is the most appropriate concept to understand the moment we live? This article tries to analyze and situate the role of education in this context. Has the school been able to meet the demands of a world in constant transformation? The amount of curricular reforms that have been implemented in several countries is a demonstration that the answer is negative, that education has not found a consistent way of meeting the demands yet. Furthermore, education can not restrict itself to meet the demands of the productive system, education should first of all, be concerned with human emancipation. Has geography been able to adapt to the transformations

\footnotetext{
*Doutor em geografia humana pela FFLCH-USP, professor de metodologia do ensino de geografia na Faculdade de Educação da USP e autor de livros educativos pela Editora Scipione.

*Doctor in Human Geography from the FFLCH-USP, professor of Geography Teaching Methodology at the College of Education at the São Paulo University. Author of teaching materials by Scipione Publishing House.
} 
of the contemporary world and at the same time explain it properly? This article discusses some of the issues related to the role of academic and educational Geography in this context.

Keywords::Information age. Changes in education. Geography Teaching.

\section{Introdução}

A educação é atravessada por diversos vetores que atuam numa sociedade em determinada época, por isso para compreender as mudanças educacionais torna-se necessário transitar em outros campos disciplinares ou áreas do conhecimento como a sociologia, a economia, a filosofia e a geografia. É necessário também enveredar por subáreas da educação como epistemologia, teorias cognitivas, ensino-aprendizagem e currículo. Mesmo sabendo dos riscos de se procurar apreender a totalidade, pela inevitável ampliação do escopo, é o que este ensaio pretenderá fazer. Seu objetivo é tentar apreender algumas das mudanças que estão ocorrendo no complexo campo educacional, particularmente no ensino de geografia, como resultado da atual revolução tecnológica.

A denominação para a acelerada transformação que estamos vivenciando em diversos setores das sociedades mundiais varia dependendo do autor: revolução informacional (CASTELLS, 1999; LOJKINE, 1995), revolução técnico-científica (SANTOS, 1996), terceira revolução industrial (KUMAR, 1997).

A questão mais importante que se buscará elucidar é: quais as consequências dessas mudanças na educação escolar? O que tem sido feito no sentido de adequar a educação aos desafios impostos pela atual revolução tecnológica? Essas mudanças implicam apenas uma adaptação da educação escolar ao sistema produtivo ou abrem brechas para que se avance no sentido de ampliar a com- preensão do mundo e a autonomia das pessoas? Qual é o papel da disciplina geografia nesse processo?

São muitos os indícios de que há uma inadequação entre as práticas pedagógicas vigentes de um modo geral e as necessidades em termos de conhecimentos e inteligências, de competências e habilidades, tanto para o exercício do trabalho como da cidadania, impostas pela atual revolução tecnológica. Há diversas indicações de que a educação vive uma crise na atual sociedade da informação. Ou seria informacional, como denomina Castells (1999), ou do conhecimento, como propõe Lévy (1998)? Como veremos ao longo do texto, a profusão de reformas educacionais postas em prática em diversos países é um dos principais indícios desta crise. As relações entre o processo de produção e difusão do conhecimento e a educação escolar são evidentes. Para compreender essas relações é importante elucidar alguns conceitos informacionais fundamentais como dados, informações, conhecimentos e inteligência, como buscaremos fazer. É de suma importância utilizar os conceitos com precisão, caso contrário perdem sua capacidade explicativa e não apreendem adequadamente a realidade.

Para analisar o papel do conhecimento no mundo contemporâneo e sua relação com as transformações em curso na educação, é importante verificar a mudança de sua natureza ao longo da história. Não se trata de um trabalho de epistemologia histórica, 
mas apenas de uma reconstituição do papel do conhecimento (e das técnicas) nos vários momentos que marcam a história humana, para compreender melhor sua importância no mundo de hoje. Para tanto nos apoiaremos nas categorias "modos de desenvolvimento" (CASTELLS, 1999) e “espaços antropológicos” (LÉVY, 1998). Numa perspectiva geográfica, e dialogando com elas, utilizaremos a categoria “meio" (SANTOS, 1996) e sua transformação ao longo da história como consequência da agregação crescente de técnicas ao território.

Serão destacados certos aspectos de algumas propostas de reforma curricular postas em prática no Canadá, nos Estados Unidos e na Espanha, que buscam dar conta das mudanças impostas pelas aceleradas transformações do mundo atual. Procuramos enfatizar a proposta brasileira, por meio dos Parâmetros Curriculares Nacionais do Ensino Médio e das Orientações Curriculares para o Ensino Médio, elaborados pelo MEC, e dar mais atenção à discussão sobre o lugar da disciplina geografia nesse processo. Merece, desde já, lembrar que a geografia é uma disciplina multiparadigmática, o que faz com que recentemente tenha apresentado propostas discrepantes em termos conceituais para a reforma curricular e isso pode enfraquecer sua capacidade explicativa.

Na busca de respostas para as questões aqui levantadas é importante que comecemos pela elucidação de alguns conceitos informacionais - dados, informações, conhecimentos e inteligências -, para logo em seguida analisarmos as categorias modo de desenvolvimento, espaços antropológicos e meio geográfico, assim como seus possíveis pontos de contato e suas inter-relações. Feito isso, discutiremos as mudanças que estão ocorrendo na educação, em sua dimensão curricular, como consequência das transformações tecnológicas em andamento nas diversas sociedades mundiais. Por fim, analisaremos a situação da geografia escolar, algumas de suas relações com a geografia acadêmica e a contribuição contraditória desta para a reforma curricular do Ensino Médio.

\section{Dados-informações-conhecimentos}

No senso comum e, às vezes, mesmo nos meios acadêmicos, os conceitos de dado, informação e conhecimento são utilizados imprecisamente, quando não de forma intercambiável. Isso ocorre, sobretudo, num mundo em que o conhecimento cada vez mais ganha relevo e somos inundados por uma crescente quantidade de informação. Hoje em dia são comuns referências à era da informação ou do conhecimento. Muitas vezes, tem-se a ideia de que esses conceitos possuem o mesmo significado. Entretanto, um breve levantamento de algumas definições mostra que não é bem assim. Castells (1999, p. 45), por exemplo, citando Porat (1977, p. 2), afirma que "informação são dados que foram organizados e comunicados.” Bem, e o que são dados? De acordo com Simon (1999, p. 17): “Um dado é uma seqüência de símbolos, é um ente totalmente sintático, não envolve semântica como na informação. Os dados podem ser representados com sons, imagens, textos, números e estruturas.” Parece evidente que para haver informação é necessário haver comunicação. Assim, podemos pensar que a informação é o dado com algum significado.

O próximo passo é a definição de conhecimento, o que é um pouco mais complexo. Castells (1999, p. 45), em seu livro $A$ sociedade em rede, diz que não tem nada a acrescentar à definição dada por Bell (1973, p.175), para quem conhecimento é “um conjunto de declarações organizadas sobre fatos ou idéias, apresentando um julgamento 
ponderado ou resultado experimental que é transmitido a outros por intermédio de algum meio de comunicação, de alguma forma sistemática.” Observe que essa definição sugere que conhecimento é igual a conhecimento científico. Perrenoud (1999, p. 8) coloca-se no outro extremo quando afirma que "conhecimento são representações da realidade que construímos e armazenamos ao sabor de nossa experiência e de nossa formação.” Como cada um vivencia a realidade e a representa de uma forma subjetiva, então, nesse caso, o conhecimento é quase como se fosse algo pessoal, arriscaria dizer, senso comum. Uma definição meio termo entre essas duas é dada por Johnson (1997, p. 48):

Conhecimento é aquilo que consideramos como real e verdadeiro. Pode ser tão simples e banal como dar o laço nos sapatos ou tão abstrato e complexo como a física de partículas. O conhecimento é importante para a sociologia porque é socialmente criado e também porque dele dependemos para nosso senso de realidade.

A partir dessas definições é razoável inferir que conhecimento não é apenas a produção científica, gerada de acordo com os cânones acadêmicos, mas também o conhecimento tácito, senso comum, intuitivo, aquele que move as pessoas em seu dia-a-dia. Entretanto, nos parece que é responsabilidade da escola avançar do senso comum ao conhecimento que se ancora nos paradigmas da ciência ou, noutras palavras, ir do conhecimento tácito ao explícito. Assim, concordamos com Lefebvre (1969, p. 67) quando afirma que "o conhecimento humano progride da ignorância à ciência”. E isto se dá por meio do estudo, da pesquisa, da descoberta. Aliás, antes dessa afirmação ele disse que o conhecimento é um fato, é prático, é social e tem um caráter histórico. Afirmou também que: “Cada época deve esforçar-se por organizar, sistematizar numa 'síntese', o conjunto de conhecimento sobre a natureza. Mas nenhuma dessas sínteses pode se pretender definitiva.” (LEFEBVRE, 1969, p. 67). Com isso, coloca a importante questão de que o conhecimento é movimento; como foi dito: é histórico. Já que estamos buscando conceituar as palavras-chave para essa discussão, coloca-se a questão de que todo conceito também é histórico e, portanto, precisa ser dinâmico. Como o conceito é sempre uma tentativa de abstrair a realidade, de reconstruí-la no plano do pensamento, caso ela mude, ele também deve mudar. De fato, como afirma Lefebvre (1969, p. 90): “Todo pensamento é movimento.”

Machado (2000), numa tentativa de definir esses termos e antes de tudo organizar sua operacionalização, propôs o que chamou de pirâmide informacional. Em sua base estão os dados, a seguir vêm as informações, depois os conhecimentos e no topo a inteligência. Os dados referem-se aos elementos qualitativos e quantitativos da realidade, podem ser acumulados e, portanto, remetem à ideia de banco. Isoladamente são desprovidos de interesse. $\mathrm{Na}$ realidade, são as pessoas que manifestam interesse por determinados dados, são elas que lhes atribuem significado, produzindo informação a partir deles. De fato, é a pergunta apropriada ao dado que permite a extração da informação pretendida. Sobre os dados, Machado (2000, p. 66) afirma que:

Seu valor informacional depende justamente da existência de pessoas interessadas, que os organizem e lhes atribuam significado, transformando-o em informação. Assim, informações já seriam dados analisados, processados, inicialmente articulados constituindo então, um segundo nível da pirâmide informacional. 
Entretanto, alerta para o fato de que o simples acúmulo de informações não garante a passagem ao terceiro nível da pirâmide, não garante a produção de conhecimentos.

Enquanto o conceito de dado remete a banco, à ideia de acumulação, informação remete a veículo, à ideia de comunicação. De fato, sem comunicação não há informação, como disse Porat (1977 apud CASTELLS, 1999). Aliás, sem comunicação também não há conhecimento. Quem é que já não tentou ler um livro numa língua estrangeira incompreendida, sem conseguir extrair nenhuma informação, nenhum conhecimento? Caso fosse uma língua que utiliza o alfabeto latino ainda seria possível identificar os dados, isto é, as letras, mas ainda assim não depreender nenhum significado, não chegar ao elemento semântico, ou seja, não extrair nenhuma informação. Pior, se o texto fosse numa língua que utiliza outro alfabeto, como o russo, o árabe ou o chinês, não se atingiria nem mesmo o dado ou o elemento sintático.

O conhecimento, o terceiro nível da pirâmide informacional, remete à ideia de teoria, de compreensão. Machado (2000, p. 67) afirma que para atingi-lo "é fundamental a capacidade de estabelecer conexões entre elementos informacionais aparentemente desconexos, processar informações, analisá-las, relacioná-las, armazená-las, avaliá-las segundo critérios de relevância, organizá-las em sistemas.” De fato, como propõe Marina (1995, p. 40), “conhecer é compreender, quer dizer, apreender o novo com o já conhecido."

O educador Nilson Machado (2000), remetendo-se ao filósofo espanhol José Antonio Marina (1995), afirma que o conhecimento é o meio para as pessoas realizarem seus projetos. Mais do que uma definição, é uma busca de operacionalização desse conceito. E falar de pessoas e projetos significa falar de valores, o que nos remete à discussão do conceito mais complexo da pirâmide informacional, aquele que se localiza em seu topo: a inteligência, ou melhor, as inteligências.

\section{Inteligências}

O conceito de inteligência é o mais difícil de ser delimitado, de ser definido. Além disso, não há uma inteligência, mas várias, daí o plural do subtítulo.

De fato, as primeiras tentativas de definir ou mais especificamente mensurar a inteligência datam do início do século XX. Em 1905, o psicólogo francês Alfred Binet (1859-1911) foi instado a elaborar um teste para medir o grau de aproveitamento dos estudantes de escolas públicas francesas. Elaborou a base para os testes de QI (Quociente de Inteligência), conhecido como Escala Simon-Binet, que depois foi aperfeiçoada e passou a ser muito utilizada no pós-guerra, sobretudo nos Estados Unidos. O teste de QI mede a relação entre a idade mental e a idade cronológica de uma pessoa. Por exemplo, se uma criança de oito anos passa num teste criado para crianças de 10 anos, então ela terá um QI de $125(10 / 8$ x $100=125)$.

Embora venham sendo utilizados há muitos anos, o problema desses testes é que veem a inteligência como uma medida unidimensional. Não por acaso Gardner (1995, p. 21) afirma: "Numa visão tradicional, a inteligência é definida operacionalmente como a capacidade de responder a itens em testes de inteligência.” Como contraponto a isso defende, já como substrato de sua teoria das inteligências múltiplas, que: "Uma inteligência implica na capacidade de resolver problemas ou elaborar produtos que são importantes num determinado ambiente ou comunidade cultural.” (GARDNER, 1995, p. 21). 
Assim, o psicólogo norte-americano propõe encarar a inteligência como um espectro de competências. Em 1983, Gardner lançou o livro Frames of mind, cuja tradução - As estruturas da mente - só saiu no Brasil em 1994, simultaneamente com As inteligências múltiplas, lançado nos Estados Unidos um ano antes. Nesses livros ele propõe que há sete inteligências: a linguística, a lógico-matemática, a corporal-cinestésica, a espacial, a musical, a interpessoal e a intrapessoal. Mais tarde Gardner (2006) passa a considerar a possibilidade de haver mais duas inteligências: a naturalista e a existencial. Todas as pessoas possuem essas inteligências e elas funcionam de forma integrada, no entanto alguns indivíduos têm maior facilidade para desenvolver uma ou mais delas. Gardner (1995) fala em "talentos mais poderosos" para aquelas pessoas que desenvolvem mais determinada(s) inteligência(s).

Na vida cotidiana há diversos exemplos de pessoas talentosas. Entretanto, como já há muito tempo alertou Adorno (1995, p. 170) no livro Educação e emancipação: "talento não se encontra previamente configurado nos homens, mas que, em seu desenvolvimento, ele depende do desafio a que cada um é submetido. Isto quer dizer que é possível ‘conferir talento' a alguém.” Isso coloca a questão da oportunidade. Cabe à escola colocar os desafios, ou seja, oferecer oportunidades para que cada pessoa possa desenvolver seus talentos ou suas inteligências.

Gardner (1995) critica não apenas a escola, sobretudo a norte-americana, e os testes de QI, por valorizarem demasiadamente o eixo linguístico-lógicomatemático, como também o psicólogo e educador suíço Jean Piaget, para quem o conceito de inteligência era sinônimo de inteligência lógico-matemática. O psicólogo norte-americano afirma que o fato de estudantes terem bom desempenho em testes de QI geralmente indica que se saem bem no ambiente escolar, onde se valoriza sobremaneira aquele eixo. Porém, isso não indica que se sairão bem após a escola, na vida de trabalhador-cidadão, na qual outras dimensões da inteligência são valorizadas, outros espectros de competências são demandados.

Finalmente, a inteligência pode ser encarada como a interação entre projetos e valores, como propõe Marina (2000, p. 14):

Inteligência é, evidentemente, a capacidade de resolver equações diferenciais, mas acima de tudo é a aptidão para organizar comportamentos, descobrir valores, inventar projetos e mantê-los, ser capaz de libertar-se do determinismo da situação, solucionar problemas, analisá-los.

Por isso Nilson Machado afirma que a inteligência está associada às pessoas e remete à ideia de projetos e valores. Para esse educador, "a inteligência encontra-se diretamente associada à capacidade de ter projetos; a partir deles, dados, informações, conhecimentos são mobilizados ou produzidos.” (MACHADO, 2000, p. 68).

Nessa linha, o que de fato interessa, o fim a ser atingido, é a realização dos projetos das pessoas e também da comunidade em que elas convivem. Evidentemente, tais projetos devem estar ancorados num conjunto de valores socialmente acordados. Sendo assim, os dados, as informações e mesmo o conhecimento passam a ser meios para a realização dos projetos pessoais e coletivos. Ou seja, estão a serviço da inteligência humana, que é plural e não pode ser encerrada num teste de papel e lápis.

Isso coloca uma questão fundamental para a educação: a definição e a operacionalização do conceito de inteligência de forma mais plural e includente abre grandes possibilidades para a produção e democratização 
do conhecimento, enfim, para a emancipação das pessoas, no sentido atribuído por Habermas (1993). Mas, antes de tudo cabe à escola oferecer as oportunidades para que os talentos ou as inteligências aflorem.

\section{Conhecimento: mudança de sua natu- reza ao longo da história}

O ser humano produz informação e conhecimento desde que iniciou sua aventura na Terra. Por isso, designações como era ou sociedade da informação (CASTELLS, 1999) ou do conhecimento (LÉVY, 1998) não deveriam ser utilizadas apenas para apreender a especificidade do momento presente, do atual período técnico-científico (SANTOS, 1996).

Castells (1999) chama a atenção para isso em seu livro a Sociedade em rede, o primeiro da trilogia A era da informação: economia, sociedade e cultura, e na tentativa de apreender as especificidades do momento presente, propõe denominá-lo de "era informacional”. Apesar da distinção conceitual, que veremos a seguir, mantém "era da informação” no título da coleção. Argumenta que títulos são dispositivos de comunicação que devem ser agradáveis e suficientemente claros, mas sem prejulgamentos, para que o leitor possa imaginar qual é o tema desenvolvido no livro.

Machado (2004, p. 123), no entanto, questiona a precisão desses conceitos quando afirma: “Às vezes, a sociedade em que vivemos é rotulada de 'sociedade do conhecimento'; outras vezes, de 'sociedade da informação’. Mas, em grande medida, ela não passa de uma 'sociedade dos bancos de dados'.”

Observando a realidade percebemos que estão ocorrendo grandes mudanças e evidentemente para compreendê-la é importante a construção de categorias e conceitos adequados, que deem conta de seu entendimento. O que há de novo hoje em dia? O que mudou no papel da informação e do conhecimento? Vejamos isso historicamente, sob a perspectiva das categorias "modos de desenvolvimento” (CASTELLS, 1999) e “espaços antropológicos” (LÉVY, 1998).

\section{Modos de desenvolvimento}

De acordo com Castells (1999, p. 34): "os modos de desenvolvimento são os procedimentos mediante os quais os trabalhadores atuam sobre a matéria para gerar o produto, em última análise, determinando o nível e a qualidade do excedente.” Assim, a história humana foi marcada por diferentes modos de desenvolvimento: o agrário, o industrial e o informacional. O que os diferencia basicamente é o fator de produção mais importante, que por sua vez está atrelado ao grau de desenvolvimento tecnológico vigente em cada um deles e ao nível de produtividade.

No modo de desenvolvimento agrário, vigente desde o neolítico, o fator de produção mais importante era a terra. O trabalho humano e, com o passar do tempo, também o de animais atuava sobre a terra com o objetivo de produzir os meios de subsistência, como os alimentos. Diferenças de produtividade, por séculos, estiveram mais ligadas à variabilidade de fertilidade natural dos solos do que aos avanços tecnológicos.

Com o advento das revoluções industriais nos séculos XVIII e XIX, a humanidade adentrou no modo de desenvolvimento industrial. A partir daí, os fatores de produção mais importantes passaram a ser as matérias-primas e fontes de energia. Isso explica porque nesse contexto 
histórico tenha se iniciado a expansão imperialista das potências industriais. As potências europeias, sobretudo, buscavam garantir acesso a fontes de matérias-primas e de energia na África e na Ásia, visando a garantir seus processos de industrialização, sua inserção no modo de desenvolvimento industrial.

Segundo a caracterização de Castells (1999), hoje estaríamos vivendo em pleno modo de desenvolvimento informacional. As sociedades do presente deixaram de ser agrárias e industriais? As matérias-primas e as fontes de energia deixaram de ser importantes? Nem é preciso dizer que continuamos a nos alimentar, logo, nossa espécie continua sendo agrária. A quantidade crescente de produtos maquinofaturados em utilização também não deixa dúvidas de que as sociedades atuais continuam sendo industriais, cada vez mais.

Com o termo informacional, Manuel Castells busca apreender o fato de que o conhecimento transformou-se no principal fator de produção do mundo atual. Em suas palavras:

No novo modo informacional de desenvolvimento, a fonte de produtividade acha-se na tecnologia de geração de conhecimentos, de processamento de informação e de comunicação de símbolos. $\mathrm{Na}$ verdade, conhecimentos e informação são elementos cruciais em todos os modos de desenvolvimento, visto que o processo produtivo sempre se baseia em algum grau de conhecimento e no processamento da informação. Contudo, o que é específico ao modo informacional de desenvolvimento é a ação de conhecimentos sobre os próprios conhecimentos como principal fonte de produtividade. (CASTELLS, 1999, p. 35).
Isso exige trabalhadores cada vez mais qualificados, já que o conhecimento é sempre pessoal e embora não sendo sujeito histórico é o principal responsável pelo aumento da oferta de bens e serviços e, sobretudo, da produtividade na era informacional. É o conhecimento o responsável pela valorização dos produtos, dos processos produtivos, dos serviços e também do território, constituindo, nesse caso, o que Santos (1996) chamou de "meio técnico-científico-informacional”.

O conjunto da humanidade é cada vez mais industrial, é crescente a oferta de bens de consumo, e a agricultura bate recordes de produtividade. A fome é um problema muito mais ligado às más políticas econômicas e às desigualdades de distribuição de renda, do que à escassez de alimentos, contrariando o que advogou Malthus no século XVIII, quando nem de longe sonhava com os avanços tecnológicos existentes na agricultura de hoje.

O que mudou é que atualmente tanto a agricultura quanto a indústria funcionam sob a lógica do informacionalismo. O modo de desenvolvimento informacional encampou os setores que eram típicos de modos de desenvolvimento precedentes. Por exemplo, a soja que o Brasil cultiva no cerrado tropical é uma criação dos técnicos da Embrapa, já que esse grão é originário de zonas temperadas. O que dizer então da soja transgênica Roundup Ready, da multinacional norte-americana Monsanto, cuja modificação genética tornou-a resistente ao herbicida Roundup, produzido por essa empresa? Esses produtos já não são naturais, mas uma criação humana, portanto, prenhes de conhecimento. Da mesma forma, um automóvel, produto por excelência da era do industrialismo, mais especificamente da segunda revolução industrial, hoje é um produto informacional. Os carros atuais, mesmo modelos mais simples e baratos, não 
têm nada a ver com os pioneiros, como o famoso Ford T. Embora o princípio básico de propulsão seja o mesmo - um motor a combustão interna queimando combustível -, computadores de bordo, freios ABS, air bag, mecanismos de navegação via GPS, entre outros equipamentos eletrônicos, transformaram o automóvel num produto informacional.

Enquanto as duas precedentes foram revoluções de energia - a primeira movida a carvão, a segunda a petróleo e a eletricidade - a atual revolução industrial é movida a conhecimento. Não que a energia tenha deixado de ser importante. Um computador, produto informacional por excelência e símbolo da atual revolução tecnológica, não funciona sem eletricidade, mas essa fonte de energia é da segunda revolução industrial. Não há uma fonte de energia nova que movimente a terceira revolução industrial, a base energética atual vem das duas anteriores. Talvez na quarta revolução industrial, ou em outras posteriores, tenhamos o desenvolvimento de uma fonte revolucionária, como foram o carvão, o petróleo e a eletricidade no passado. Quem sabe o hidrogênio ou a energia solar, fontes inesgotáveis e limpas.

Sem dúvida, o conhecimento é o grande motor da era informacional ou, com o perdão da redundância, da era do conhecimento.

\section{Espaços antropológicos e meios geográficos}

O filósofo francês Pierre Lévy, na tentativa de apreender a história dos seres humanos sobre o planeta e suas relações com o cosmo, os mitos, os ritos, com o território, a política e a economia e evidentemente com o conhecimento, fala em "espaços antropológicos”. Mas, o que seria um espaço antropo- lógico? Segundo Lévy (1998, p. 22): “É um sistema de proximidade (espaço) próprio do mundo humano (antropológico), e portanto dependente de técnicas, de significações, da linguagem, da cultura, das convenções, das representações e das emoções humanas.” São espaços de significações que se constituíram progressivamente ao longo da história humana e se estendem ao conjunto da humanidade. São quatro: a Terra, o Território, o Espaço das mercadorias e o Espaço do saber. Esses espaços são irreversíveis e essa irreversibilidade é que permite qualificá-los de espaços antropológicos. É uma construção humana e coexistem em toda parte, embora diferentemente. O Espaço do saber foi o último a se constituir, ou melhor, ainda está em construção e nada garante que venha a ser constituído. Assim, na prática a irreversibilidade vale apenas para os três primeiros.

A Terra foi o primeiro espaço antropológico construído. Terra, aqui, deve ser entendida como o mundo das significações, construído a partir do paleolítico e ancorado na linguagem, nos mitos e nos ritos. A Terra, segundo Lévy (1998), não é o planeta nem mesmo a biosfera; é o cosmo, o espaço-tempo de relações. Naquela época o homem era nômade e sua principal atividade era caçar. Como início da construção da identidade dos humanos se destaca, além do vínculo com o cosmo, o vínculo de filiação, de aliança com outros homens.

De acordo com Lévy (1998, p. 115): “Nossa espécie produziu a Terra, elaborando o mundo humano como tal." Em lugar de Terra, também poderíamos falar em espaço geográfico, que começou a ser construído desde o início da civilização a partir do meio natural. À medida que o espaço foi sendo construído, que o homem foi lhe agregando técnicas, o meio natural foi se transformando em meio técnico, como propôs Santos (1996). Além da dimensão simbólica atribuída à Terra, depreende-se que há também uma 
dimensão geográfica, quando Lévy (1998, p. 22) afirma: "Só os seres humanos vivem sobre a Terra, os animais habitam em nichos ecológicos.”

O Território, como espaço antropológico, começou a ser construído do neolítico para cá, porém trata-se de um neolítico atemporal, não o da história, já que a difusão das inovações é desigual. Santos (1996) alerta para o fato de que as técnicas se difundem de forma desigual no território ${ }^{1}$. Já o Território começou a ser construído quando o ser humano iniciou o desenvolvimento da agricultura, a construção de cidades, a organização de Estados e a criação da escrita. Isso marca o início da "civilização", quando o homem deixou de ser nômade e tornou-se sedentário. A sedentarização demandou o controle de territórios, passando pela conquista e ocupação, o que levou à constituição dos primeiros impérios. Não por acaso Lévy (1998) menciona que enquanto o símbolo da Terra era o caçador pintando um grande animal na parede de uma gruta, o símbolo do Território era Sargon de Agadés, primeiro imperador da história, que unificou por meio de suas conquistas todas as cidadesEstados da Mesopotâmia.

Com isso no processo de construção da identidade do ser humano, além do nome, que remete à filiação, passa a ser importante a definição de um "endereço", ou seja, a localização no território ou no Território dos sedentários ou dos contribuintes, como diz Lévy (1998). Numa perspectiva geográfica, pode-se dizer que a partir daí o homem começou a construir o meio técnico, com a gradativa implantação de objetos - cidades, campos agrícolas, canais, estradas, castelos, igrejas, fortalezas etc. - no espaço geográfico. Mas isso ainda é muito incipiente. A pro-

\footnotetext{
${ }^{1}$ Usaremos território, em caixa baixa, como um conceito geográfico, e Território, em caixa alta, como espaço antropológico, como propõe Pierre Lévy.
}

pósito, Santos (1996) reserva a designação de meio técnico à fase posterior à invenção e ao uso da máquina. Porém, abre uma brecha para chamarmos de meio técnico a fase anterior ao maquinismo, ao afirmar que "a inexistência de artefatos mais complexos ou de máquinas não significa que uma dada sociedade não disponha de técnicas.” (SANTOS, 1996, p. 187). Podemos dizer, então, que o meio técnico generalizou-se após as revoluções industriais, mas mesmo a partir daí, de forma desigual. Fazendo um paralelo com Castells (1999), pode-se afirmar que a origem do Território, como espaço antropológico, coincide com o início do modo de desenvolvimento agrário.

O terceiro espaço antropológico, o Espaço das mercadorias, começou a ser construído a partir do século XVI, coincidindo com a expansão marítima europeia e com o início do capitalismo. Em sua etapa comercial esse sistema organizou um espaço de fluxos - de matérias-primas, de energia, de mercadorias, de capitais, de mão-de-obra e de informações. O homem continuou sedentário, como espécie, mas ao mesmo tempo tornou-se viajante: muitos de seus membros passaram a atingir lugares cada vez mais distantes. Contrariando Pierre Lévy, só então, como resultado das grandes navegações, é que se inicia de fato a construção da Terra, pelo menos como sinônimo de mundo. Antes disso existia um planeta, mas que não era conhecido inteiramente por nenhum povo - era ignorado como um todo -, e vários mundos. Exagerando um pouco, pode-se dizer que havia tantos mundos quantos eram os povos. De fato, o mundo estava restrito quase que somente à escala do lugar ou, quando muito, da região. Então, pode-se dizer que a Terra, como espaço antropológico, na realidade era sinônimo de mundo conhecido por um povo. No fundo, não há discordância, afinal 
Lévy (1998) não fala em Terra como espaço geográfico, fala como espaço antropológico. De qualquer forma, ainda pensando geograficamente, a sinonímia entre Terra, planeta, mundo e globo só começou a ser construída no Espaço mercantil, ou seja, sob o capitalismo, que é expansionista por natureza, como salientam Moraes e Costa (1987, p. 138):

Expansão e concentração são, assim, fundamentos do desenvolvimento do capitalismo. A tendência do desenvolvimento das trocas e da circulação em geral é a de incorporar ao circuito econômico, espaços cada vez mais dilatados. Já foi discutido o processo de formação da história universal, com a mundialização da economia e a globalização dos fluxos. A internacionalização constitui o momento mais avançado do processo de valorização do espaço.

Castells (1999) situa o início do modo de desenvolvimento industrial um pouco mais tarde, com o advento das revoluções industriais no século XVIII. É exatamente a partir daí que, segundo Santos (1996), se constituiu o meio técnico, com a crescente agregação de objetos técnicos ao espaço geográfico, com sua contínua mecanização, com o crescimento das cidades, das indústrias e de outras infraestruturas que dão suporte à produção e à circulação de mercadorias e de pessoas. Já vimos com Castells (1999) que o advento do modo de desenvolvimento industrial torna fundamental o acesso a fontes de matérias-primas e de energia, reforçando o espaço de fluxos, proposto por Lévy (1998), e ampliando o meio técnico, sugerido por Santos (1996).

Dando continuidade ao processo histórico de construção da identidade do humano, com o advento do Espaço mercantil, além do nome e do “endereço”, passa ser cada vez mais importante a definição da profissão, que crescentemente é assalariada. Se na Terra ou no meio natural, o homem era nômade; se no Território ou nos primórdios do meio técnico, ou ainda durante o modo de desenvolvimento agrário, o homem era essencialmente agricultor; no Espaço mercantil, no meio técnico por excelência ou no modo de desenvolvimento industrial, o homem passa a ser cada vez mais operário.

Lévy não menciona, mas outro importante construtor de identidades humanas, que tem tudo a ver com o Território, embora tenha se consolidado no Espaço mercantil, é a nação. Com a consolidação dos Estados modernos, um dos mais importantes sinais de identidade é o pertencimento a uma nação. Como fenômeno "construído essencialmente pelo alto”, como diz Hobsbawn (1990, p. 20), os Estados bem que tentaram coincidir a nação com os limites de seu território, embora, muitas vezes, em vão, haja vista a grande quantidade de países plurinacionais. Sendo assim, ao nome, ao “endereço” e à profissão deve-se acrescentar a nacionalidade, que é o sinal de pertencimento a um povo, a uma nação, em sentido antropológico, ou mais especificamente ao um Estado territorial, em sentido jurídico-político. De acordo com Hobsbawn (1990, p. 32): “A equação nação $=$ Estado = povo e, especialmente, povo soberano, vinculou indubitavelmente a nação ao território, pois a estrutura e a definição dos Estados eram agora essencialmente territoriais.”

O último dos espaços antropológicos é o Espaço do saber, que Lévy, sem meias palavras, diz que ainda não existe: "Sejamos francos: o Espaço do saber não existe. É, no sentido etimológico, uma u-topia, um não lugar. Não se realiza em parte alguma (1998, p. 120).” Não existe porque ainda não adquiriu autonomia e irreversibilidade como os anteriores, porém trata-se de uma perspectiva para o futuro que pode realizarse ou não, mas que já existe em germe. 
Segundo Levy, está nascendo com o crescente desenvolvimento da inteligência coletiva, com a construção de universos virtuais, de ciberespaços em que se buscam formas inéditas de comunicação, de solidariedade e de produção de subjetividades. O homem passa a ser cada vez mais um viajante virtual, navegando no ciberespaço, embora também viaje cada vez mais no espaço concreto, geométrico.

Nesse novo espaço antropológico, ainda em gestação, o conhecimento é a principal fonte de riquezas. Nas palavras de Lévy (1998, p. 25): "Os conhecimentos vivos, os savoir-faire e competências dos seres humanos estão prestes a ser reconhecidos como a fonte de todas outras riquezas.” Como vimos, Castells (1999) também afirma que o conhecimento é o fator de produção mais importante no modo de desenvolvimento informacional. Santos (1996), numa perspectiva mais territorial, chama a atenção para a recente emergência do meio técnico-científico-informacional, no atual período do capitalismo, com objetos técnicos marcados por crescente incorporação de ciência e de técnica, que têm sua expressão máxima nas cidades globais e nos tecnopolos ou parques científicos.

Todas essas mudanças com relação ao conhecimento, seja na vida das pessoas, das empresas, das instituições e do território, são frutos da terceira revolução industrial (KUMAR, 1997), para seguir a cronologia histórica, ou da revolução informacional (CASTELLS, 1999) ou técnico-científica (SANTOS, 1996).

Para Castells a nova "matéria-prima" é o conhecimento, enquanto que para Lévy é o ser humano. Segundo palavras deste:

O setor de futuro da produção antrópica caminha sobre duas pernas indissociáveis: a cultura das qualidades humanas - especialmente as competências - e a administração de uma sociedade na qual se possa viver. É como se o humano, em toda a sua extensão e variedade, voltasse a se tornar matéria-prima. (LÉVY, 1998, p. 44).

Causa estranhamento o fato de que o referido autor utilize o verbo "voltasse", porque na história humana, desde a Antiguidade, e de forma mundializada e extremamente violenta, durante o Espaço mercantil, o ser humano foi "matériaprima” para ser explorado, primeiramente como escravo (aí mais propriamente como mercadoria) e depois, já sob o industrialismo, como mão de obra barata. Mas, quando ele fala em ser humano como "matéria-prima" é no sentido de que este passe a ser o centro das preocupações, a fonte de todo o valor, o alvo de todos os projetos. Que o ser humano passe a ser o senhor de seu destino, plenamente emancipado e tendo suas competências valorizadas e sua qualidade de vida melhorada. Lévy (1998) espera que isso se realize no Espaço do saber. Nós também, mas observando a realidade do momento presente, temos de admitir que se trata de uma visão muito otimista.

\section{Mudanças na educação}

Voltando à introdução deste artigo, a propósito da existência de uma crise na educação, pode-se dizer que se trata de um diagnóstico banalizado e até antigo. Em 1958, a filósofa alemã Hannah Arendt, que desde 1940 vivia nos Estados Unidos, após fugir do nazismo, escreveu um texto cujo título é precisamente: A crise na educação. Tratava da realidade norte-americana, mas sugeria que podia ser um problema de outros países. Em suas palavras: 
A crise geral que acometeu o mundo moderno em toda parte em quase toda esfera da vida se manifesta diversamente em cada país, envolvendo áreas e assumindo formas diversas. Na América, um de seus aspectos mais característicos e sugestivos é a crise periódica na educação, que se tornou, no transcurso da última década pelo menos, um problema político de primeira grandeza, aparecendo quase diariamente no noticiário jornalístico. (ARENDT, 2005, p. 221).

O educador canadense Kieran Egan, escrevendo quase meio século depois, também aponta uma crise na educação, uma ineficiência das escolas. O subtítulo de seu livro A mente educada, lançado no Brasil em 2002, é: os males da educação e a ineficiência educacional das escolas. Mudam apenas os diagnósticos sobre o porquê da crise. Egan (2002) aponta a incompatibilidade entre o objetivo de socialização, o ideal platônico de busca desinteressada da verdade, de cultivo do intelecto, e o ideal russeauniano de estímulo ao desenvolvimento do potencial pessoal do aluno. Noutras palavras, o antigo embate academicismo $\mathrm{x}$ pragmatismo. Arendt (2005), entre outros fatores, aponta a negligência com a formação dos professores em suas respectivas disciplinas. Para ela, a escola deveria ser mais platônica e menos russeauniana.

A profusão de reformas educacionais que estão sendo discutidas e/ou implementadas em diversos países é um forte indício dessa crise ou inadequação à era informacional, marcada por crescente competição entre trabalhadores e empresas, lugares e nações e na qual o conhecimento ganha cada vez mais relevância.

Em 1997, o Ministério de Educação do Quebec, Canadá, elaborou um documento-Québec Schools on Course: Educational Policy Statement - propondo uma reforma no sistema de ensino provincial (fundamental e médio). Quais são as razões que levaram o governo dessa província canadense a buscar uma redefinição da missão de suas escolas e uma revisão curricular? Com a palavra Pauline Marois, Ministra da Educação:

First, knowledge plays and will continue to play a central role in our society. Students must be given the opportunity to master essential, even complex learning, but first and foremost basic skills and knowledge, at the appropriate time in their schooling. Second, students must be prepared to assume their role as responsible citizens by learning and sharing common values. Finally, students must be made aware of the global challenges which have and impact on all societies by gradually developing their ability to think and act in a manner that transcends current trends and personal interests. (CANADÁ, 1997, p. 3).

Nos Estados Unidos, o Departamento de Educação elaborou em 2004 o documento No Child Left Behind para orientar mudanças no sentido de reforçar a qualidade de ensino ministrado nas escolas públicas de nível básico. Rod Paige, Secretário de Educação, destacando a importância da educação para a democracia e a economia do país e buscando inspiração nos "Pais Fundadores” da nação americana, declara:

Education is one of the most important functions of government. It was a concern of the early settlers, and a focus of the Founding Fathers in writing the Constitution precisely because our democracy is dependent on an educated public. [...] The Founding Fathers were correct: Education is necessary for the growth and prosperity of our country. As education more inclusive and of better quality, it has enhanced American economic and political leadership. (U. S., 2004, p. 2). 
A preocupação de garantir a competitividade do país e mantê-lo na dianteira econômica e tecnológica na economia globalizada aparece claramente no seguinte trecho: "Satisfying the demand for highly skilled workers is the key to maintaining competitiveness and prosperity in the global economy." (U. S., 2004, p. 2).

Também em 2004, o governo espanhol, por meio do Ministerio de Educación y Ciencia, produziu o documento Una educación de calidad para todos $y$ entre todos: propuestas para el debate, com o objetivo de subsidiar as discussões na sociedade com vistas à votação de um Projeto de Lei de reforma educacional. A então Ministra da Educação, Maria Jesús San Segundo Gómez de Cadiñanos, assim justificou a necessidade da reforma:

Para alcanzar una ciudadanía social y economicamente activa es imprescindible una educación en permanente mejora, que ofrezca a los jóvenes más y mejor formación. Debemos procurar que todos los estudiantes obtengan los mejores resultados de que son capaces. Tenemos que continuar aproximando las tasas de titulación en todos los niveles educativos a las que se alcanzan en los países mejor situados de nuestro entorno y a las que la Unión Europea se propone como objetivo para los próximos años. El esfuerzo debe ser particularmente intenso en la enseñanza básica y en la educación secundaria postobligatoria. Pero no sólo debemos ofrecer más formación para todos, ha de ser también de mayor calidad, para que permita a nuestros jóvenes incorporarse del modo más satisfactorio posible al mundo laboral y a una sociedad cambiante y fuertemente interrelacionada con otras culturas. (ESPAÑA, 2004, p. 3-4).

No texto da nova reforma educacional - Ley Orgánica de Educación, aprovada em 2006 - ficou mais patente a busca de adaptação às mudanças ensejadas pela sociedade do conhecimento:

A la vista de la evolución acelerada de la ciencia y la tecnología y el impacto que dicha evolución tiene en el desarrollo social, es más necesario que nunca que la educación prepare adecuadamente para vivir en la nueva sociedad del conocimiento y poder afrontar los retos que de ello se derivan. (ESPAÑA, 2006, p. 17160).

No Brasil, os Parâmetros Curriculares Nacionais (PCN) para a educação básica foram elaborados no final dos anos 1990. Nos do ensino médio (PCNEM), lançados em $1999^{2}$, ficou mais evidente a necessidade de reforma curricular como uma imposição da revolução tecnológica e da crescente importância do papel do conhecimento nas relações sociais. De acordo com o documento:
A denominada 'revolução informática' promove mudanças radicais na área do co- nhecimento, que passa a ocupar um lugar central nos processos de desenvolvimen- to, em geral. [...] As propostas de reforma curricular para o Ensino Médio se pautam nas constatações sobre as mudanças no conhecimento e seus desdobramentos, no que se refere à produção e às relações so- ciais de um modo geral. (BRASIL, 2002, p. 15).

Observe que as justificativas do documento brasileiro para a reforma educacional são em linhas gerais as mesmas que constam nas propostas canadense, norte-americana e espanhola. Aliás, as palavras referentes ao papel central do conhecimento são quase idênticas às da proposta canadense.

\footnotetext{
${ }^{2}$ A primeira versão dos Parâmetros Curriculares Nacionais do Ensino Médio (PCNEM) foi lançada em 1999; depois, em 2002, o MEC publicou outra versão com pequenas modificações de texto, a qual foi utilizada nas transcrições deste artigo.
} 
O ensino ministrado nas escolas brasileiras, de forma geral, ainda responde às necessidades da segunda revolução industrial, da era fordista, quando atualmente vivenciamos a terceira revolução industrial, a era pós-fordista ou da produção flexível (HARVEY, 1993). De acordo com Pontuschka (1999, p. 112):

A escola da fábrica do século passado ainda está aí e não dá conta da formação desse jovem. Há que se pensar em um ensino que forme o aluno do ponto de vista reflexivo, flexível, crítico e criativo. Não é uma formação para o mercado de trabalho apenas, mas um jovem preparado para enfrentar as transformações cada vez mais céleres que certamente virão.

Na verdade, essas transformações já chegaram. Consequentemente são outras as demandas, não apenas para o trabalhador, mas também para o cidadão, embora não seja aconselhável separar esses dois sujeitos sociais, porque, na realidade, são duas dimensões da pessoa. O próprio PCNEM faz essa constatação, quando afirma:

Nas décadas de 60 e 70, considerando o nível de desenvolvimento da industrialização na América Latina, a política educacional vigente priorizou, como finalidade para o Ensino Médio, a formação de especialistas capazes de dominar a utilização de maquinarias ou de dirigir processos de produção. Esta tendência levou o Brasil, na década de 70, a propor a profissionalização compulsória, estratégia que também visava a diminuir a pressão da demanda sobre o Ensino Superior.

Na década de 90, enfrentamos um desafio de outra ordem. O volume de informações, produzido em decorrência das novas tecnologias, é constantemente superado, colocando novos parâmetros para a formação dos cidadãos. Não se trata de acumular conhecimentos. (BRASIL, 2002, p. 15).
A LDB 5692/71 expressava a realidade da segunda revolução industrial, então em curso, e procurava dar respostas às suas necessidades; a LDB 9394/96, que é orientadora do PCNEM, expressa a terceira revolução industrial em andamento e procura dar conta das novas demandas ensejadas por ela.

Porém, como o PCNEM não foi absorvido pelo sistema de ensino, em 2004 o Ministério da Educação convocou diversos especialistas para a elaboração de outra proposta: Orientações Curriculares do Ensino Médio. Esse documento serviu de base para o debate sobre os rumos do novo ensino médio, como tem sido chamado.

O PCNEM “não se concretizou”, para usar as palavras do então Secretário de Educação Básica, Francisco das Chagas Fernandes, na apresentação do documento Orientações Curriculares do Ensino Médio,

[...] por não ter conseguido, nas diferentes instâncias do Ensino Médio, aprofundar análise consistente que permitisse esclarecer e orientar as escolas, bem como, promover o estudo do documento $\mathrm{e}$ discutir as possibilidades didáticopedagógicas, por ela apresentadas, junto ao professor na execução da sua prática docente. (BRASIL, 2004, p. 6).

Parece-nos que o Secretário acerta no diagnóstico do problema, mas erra na explicação de suas causas e consequentemente na prescrição da solução. Mesmo que Egan (2002) não tenha razão em seu diagnóstico sobre a crise da educação, ou que tenha apenas para a América Anglo-Saxônica, ele oferece importantes indícios para a reflexão sobre a realidade brasileira, quando fala das incompatibilidades vigentes na educação. A proposta do PCNEM não se concretizou porque apresenta uma incompatibilidade intrínseca. O documento propõe um ensino interdisciplinar, como se percebe: 
Quando a LDB destaca as diretrizes curriculares específicas do Ensino Médio, ela se preocupa em apontar para um planejamento e desenvolvimento do currículo de forma orgânica, superando a organização por disciplinas estanques e revigorando a integração e articulação dos conhecimentos, num processo permanente de interdisciplinaridade e transdisciplinaridade. (BRASIL, 2002, p. 31).

No entanto, toda a cultura vigente nas escolas está ancorada num currículo disciplinar. As aulas são divididas por disciplinas, os livros didáticos são organizados por disciplinas e a longa tradição cartesiano-positivista da formação acadêmica dos professores é disciplinar. Além disso, o próprio PCNEM, apesar de defender a interdisciplinaridade, na versão complementar publicada em 2002, chamada de PCN + ensino médio (BRASIL, 2002a), propõe uma organização curricular em eixos temáticos essencialmente disciplinares. Essa incoerência é apontada no documento Orientações Curriculares do Ensino Médio, quando analisa a proposta para a geografia, mas ela também ocorre nas outras disciplinas:

[...] a forma de organização dos conteúdos, como está apresentada nas páginas 66 a 68 dos PCN +, em análise, não contém, em si mesma, a proposta de interdisciplinaridade defendida nos parâmetros uma vez que os conteúdos continuam a ser apresentados por disciplinas. Além disso, o livro didático, importante instrumento de trabalho dos professores desse nível de ensino, também são produzidos e utilizados em componentes curriculares específicos. (BRASIL, 2004, p. 325).

O equilíbrio do par cultura-educação ou conservação-transformação não é trivial. Na escola há uma cultura educacional, uma “gramática escolar” no dizer de Tyack e
Cuban (1975 apud VIÑAO, 2003), isto é, hábitos e costumes consolidados ao longo do tempo sobre modos de ensinar, seleção de conteúdos, formas de avaliação etc., que é muito difícil de modificar. Evidentemente que a mudança pode e deve ocorrer, mas talvez não ocorra na velocidade que os elaboradores dos documentos e o MEC esperavam. Para a implantação de um ensino interdisciplinar seria necessário primeiro que os professores fossem preparados para essa mudança. Devem ser orientados, como propõe o Secretário de Educação Básica, mas é fundamental a elaboração de novos materiais didáticos, porque todos sabemos do peso que os livros educativos têm na relação ensino-aprendizagem. Por diversas razões, é muito difícil para os professores elaborarem seu próprio material didático. E mais importante: de médio a longo prazo é fundamental reavaliar a fragmentada formação universitária dos professores, calcada no paradigma cartesiano-positivista.

Entretanto, o que é mais preocupante são as incompatibilidades e incoerências presentes nos próprios documentos elaborados com o intuito de orientar a mudança. Não é de se estranhar que eles não sejam absorvidos nas escolas. Aliás, o fato de existirem tantos e tão extensos documentos já é sintomático. O PCNEM, elaborado em 1999, “não se concretizou”, então o MEC elaborou o PCN + ensino médio, em 2002, que aparentemente aprofundou, ou explicitou, as contradições do documento anterior, tornando necessária a elaboração de uma nova proposta - as Orientações Curriculares de 2004 - para ser debatida e servir de base para um novo documento publicado em 2006 as Orientações Curriculares para o Ensino Médio.

A tensão entre cultura e educação aflora em qualquer proposta de reforma educacional e, situadas no campo da cultura, afloram também questões epistemológicas, 
teórico-metodológicas e mesmo ideológicas. Como nos lembra Tomaz Tadeu da Silva, na apresentação do livro de Goodson (1995, p. 8): “O currículo não é constituído de conhecimentos válidos, mas de conhecimentos considerados socialmente válidos.” O que é ensinado nas escolas é sempre uma seleção de conhecimentos a partir de um universo cultural mais amplo. Apple (2006) chama isso de “tradição seletiva”. A questão é: válidos para quem? Silva mesmo responde, quando afirma que:

Nessa perspectiva, o currículo deve ser visto não apenas como a expressão ou a representação ou o reflexo de interesses sociais determinados, mas também como produzindo identidades e subjetividades sociais determinadas. O currículo não apenas representa, ele faz. É preciso reconhecer que a inclusão ou exclusão no currículo tem conexões com a inclusão ou exclusão na sociedade. (GOODSON, 1995, p. 10).

Em outras palavras, o currículo não é neutro.

Como sabemos, as rápidas mudanças impostas pela revolução técnico-científica ou informacional têm criado novas exigências aos trabalhadores e cidadãos em termos de formação, habilidades, competências, atitudes e consciência acerca de direitos e deveres. Além dos governos, organismos internacionais como ONU também têm elaborado propostas de mudanças para o ensino, buscando dar conta dessas novas demandas, como fica patente no Relatório para a UNESCO da Comissão Internacional sobre Educação para o século XXI (DELORS, 2001).

Evidentemente, as empresas são as maiores interessadas em trabalhadores formados segundo esses novos paradigmas. Uma pesquisa da CPM-Market Research feita para o então Projeto Aprendiz (atual ONG Cidade Escola Aprendiz), realizada em 1998, entrevistou 178 profissionais entre os quais jornalistas, especialistas em recursos humanos e empresários. Foram indagados sobre quais eram as características mais relevantes para o trabalhador do futuro, do novo milênio, nas categorias formação, habilidades, atitudes e personalidade. $\mathrm{Na}$ categoria formação a frase mais mencionada (79\% das menções) foi: "nunca parar de aprender”. Ou seja, o trabalhador do futuro, na verdade, do presente, pois essa realidade já está posta, não pode parar de aprender e a clássica separação entre a escola e o trabalho, vigente na era fordista, não faz mais sentido atualmente, um período marcado pela produção flexível. Apesar de seu reduzido escopo, o resultado dessa pesquisa é um indício das novas tendências da atual era informacional e vai ao encontro da proposta do Relatório para a UNESCO: “A educação deve transmitir, de fato, de forma maciça e eficaz, cada vez mais, saberes e saber-fazer evolutivos, adaptados à civilização cognitiva, pois são as bases das competências do futuro.” (DELORS, 2001, p. 89). Fica mais evidente essa tentativa de dar respostas à realidade quando o mesmo relatório enuncia os quatro pilares da educação:

Para poder dar resposta ao conjunto das suas missões, a educação deve organizarse em torno de quatro aprendizagens fundamentais que, ao longo de toda a vida, serão de algum modo para cada indivíduo, os pilares do conhecimento: aprender a conhecer, isto é adquirir os instrumentos da compreensão; aprender a fazer, para poder agir sobre o meio envolvente; aprender a viver juntos, a fim de participar e cooperar com os outros em todas as atividades humanas; finalmente aprender a ser, via essencial que integra as três precedentes. (DELORS, 2001, p. 89-90). 
O PCNEM também faz menção a esses quatro pilares da aprendizagem e destaca a importância do "aprender a aprender", “de uma aprendizagem permanente, de uma formação continuada, considerando como elemento central dessa formação a construção da cidadania em função dos processos sociais que se modificam.” (BRASIL, 2002, p. 25).

A revolução técnico-científica ou informacional tem imposto mudanças nos produtos, nos serviços, nos processos produtivos, enfim, nas relações de produção e também nas relações sócio-espaciais. Logo, é razoável supor que imporia mudanças também na educação, na relação ensino-aprendizagem, até porque a escola não está isolada do mundo e, de uma forma ou de outra, têm procurado ao longo da história dar respostas às demandas da sociedade, sobretudo a capitalista, como fica evidente pelos documentos elaborados pelos ministérios da educação dos países mencionados. Independentemente da instrumentalização da escola pelo sistema produtivo - que é real, embora a educação tenha um sentido muito maior do que simplesmente dar respostas às necessidades da economia - as mudanças ensejadas pela revolução informacional impõem um novo enfoque sobre o conhecimento e, sobretudo, sobre sua transmissão ou construção. Apoiando-se na teoria Piagetiana, propõe Becker (2003, p. 21):

Os conteúdos devem estar a serviço do aumento da capacidade de aprendizagem (construção de estruturas) e não constituir um fim em si mesmos: as estruturas permanecem ou são subsumidas por estruturas mais capazes; os conteúdos caducam. Por isso, o ensino deve organizar-se, primeiramente, no sentido do conhecimento-estrutura e só secundariamente no sentido do conhecimento-conteúdo.
Nessa mesma linha, o Relatório para a UNESCO defende que:

[...] uma resposta puramente quantitativa à necessidade insaciável de educação - uma bagagem escolar cada vez mais pesada já não é possível nem mesmo adequada. Não basta, de fato, que cada um acumule no começo da vida uma determinada quantidade de conhecimentos de que possa abastecer-se indefinidamente. É, antes, necessário estar à altura de aproveitar e explorar, do começo ao fim da vida, todas as ocasiões de atualizar, aprofundar e enriquecer estes primeiros conhecimentos, e de se adaptar a um mundo em mudança. (DELORS, 2001, p. 89). melhante:

O PCNEM também faz proposta se-

Não há o que justifique memorizar conhecimentos que estão sendo superados ou cujo acesso é facilitado pela moderna tecnologia. O que se deseja é que os estudantes desenvolvam competências básicas que lhes permitam desenvolver a capacidade de continuar aprendendo. (BRASIL, 2002, p. 25).

Como se vê, o educador suíço ainda tem muito a contribuir para esse debate $\mathrm{e}$ suas propostas de construção do conhecimento, de desenvolvimento de estruturas de assimilação, devem ser consideradas como uma possível resposta às novas necessidades em termos de competências e habilidades postas pela era informacional, a despeito das restrições apontadas por Gardner (1995) quanto à questão das inteligências. Como afirma Becker (2003, p. 17): “A obra de Piaget talvez seja a mais acabada manifestação a favor do ‘deixar aprender' ou do 'aprender a aprender'.” Evidentemente que as contribuições de outros teóricos cognitivistas, entre os quais Vigotski (2003) e Ausubel (2003), não devem ser desprezadas. 


\section{E a Geografia: qual é seu papel?}

A geografia escolar possui uma longa tradição de ensino enciclopédico e descontextualizado, já vigorosamente criticada por Lacoste (1999), inclusive apontando o aspecto ideológico da "geografia dos professores". A partir de agora essa disciplina também vem sendo convidada a contribuir com seu arcabouço teóricometodológico renovado - seus conteúdos, conceitos e categorias - para auxiliar os alunos a desenvolverem suas competências e habilidades, suas inteligências, suas estruturas de assimilação, enfim, a aprenderem a aprender. De que forma a geografia pode contribuir para isso? Apesar de a renovação crítica da geografia acadêmica completar mais de três décadas e muito ter sido feito no sentido de transformar o ensino da geografia escolar, ainda não chegamos a um consenso, ou melhor, ainda não encontramos caminhos consistentes, mesmo que no dissenso. Como questiona Pontuschka (1999, p. 112):

Estamos terminando o século XX e continuamos a nos fazer perguntas antigas sobre o ensino-aprendizagem da geografia. Que conteúdos ensinar? Que método utilizar? Que linguagens priorizar? Como sensibilizar os alunos para a importância do conhecimento da geografia para a sua vida em suas múltiplas dimensões?”

Atualizando seu texto, já estamos começando o século XXI, mas as dúvidas permanecem e a relação da geografia acadêmica com a geografia escolar nem sempre é fácil. Vejamos algumas evidências.

No documento Orientações Curriculares do Ensino Médio (BRASIL, 2004), o trecho que analisa a disciplina geografia não concorda com o enfoque teórico-metodológico da proposta do PCN + (BRASIL, 2002a), que é uma tentativa do MEC de esmiuçar o PCNEM (BRASIL, 1999, 2002). O texto elaborado pelos professores Eliseu Savério Sposito e Maria Encarnação Sposito, do Departamento de Geografia da UNESP (Presidente Prudente), critica a definição dos conceitos-chave e a proposta dos eixos temáticos da geografia, que estariam baseados no conceito de espaço geográfico elaborado por Milton Santos. Os autores argumentam que como esse conceito está ancorado numa forma estruturalista de pensar, dificultaria o tratamento interdisciplinar. Em suas palavras:

A organização dos eixos temáticos em Geografia e seus desdobramentos em subtemas, por exemplo, estão baseados, fundamentalmente, no conceito de espaço geográfico elaborado por Milton Santos e se prende a essa forma de pensar, de base estruturalista. Como as bases teóricas dos outros campos disciplinares não são, necessariamente, as mesmas e, em função do "caráter fechado" que caracteriza a forma de estruturalista de elaborar o pensamento, a relação interdisciplinar com os outros componentes fica dificultado. (BRASIL, 2004, p. 325).

Em outra passagem, insistindo na crítica à metodologia adotada, os autores afirmam:

Uma segunda apreciação sobre os conceitos estruturantes do documento leva à reflexão sobre a tendência teórica adotada. Ela se baseia, ao eleger o espaço geográfico como conceito norteador dos demais conceitos, numa concepção de Geografia que se consolidou no Brasil pela corrente estabelecido pelo pensamento de Milton Santos. Não é demérito nenhum se orientar por tal perspectiva; no entanto, arrisca-se esquecer a sociedade como objeto de estudo da geografia, ao se privilegiar forma, função, estrutura e processo, elementos fundamentais para 
a leitura do espaço geográfico, segundo essa perspectiva. (BRASIL, 2004, p. 337).

Quase no final do documento, ainda reafirmam: "Como afirmado anteriormente, ao se orientar por tal tendência teórica arrisca-se negligenciar a sociedade como objeto científico e filosófico de uma proposta curricular, ficando limitado apenas à compreensão do espaço geográfico.” (BRASIL, 2004, p. 337).

Mas, como compreender a sociedade sem compreender o espaço geográfico? Ou como compreender o espaço geográfico sem compreender a sociedade? Esses conceitos não são separados, não podem ser compreendidos e operacionalizados isoladamente. O próprio Milton Santos nunca afirmou isso, muito pelo contrário. Desde seu famoso texto no Boletim Paulista de Geografia n. 54, quando lançou o conceito de formação sócio-espacial, até seu último livro antes de falecer, ele defendeu a inseparabilidade entre a sociedade e o espaço geográfico:

Como pudemos esquecer por tanto tempo esta inseparabilidade das realidades e das noções de sociedade e de espaço inerentes à categoria da formação social? Só o atraso teórico conhecido por essas duas noções pode explicar que não se tenha procurado reuni-las num conceito único. Não se pode falar de uma lei separada da evolução das formações espaciais. De fato, é de formações sócio-espaciais que se trata. (SANTOS, 1977, p. 93).

No livro Por uma geografia nova, o autor reafirma isso:

A sociedade não se pode tornar objetiva sem as formas geográficas. Por outro lado, os objetos que constituem a paisagem orientam, depois, a evolução da própria sociedade, fato que não tem sido suficientemente nem sistematicamente indicado. (SANTOS, 1980, p. 199).
Avançando sua leitura do mundo, no livro A natureza do espaço, Santos (1996, p. 51) propõe que: “O espaço é formado por um conjunto indissociável, solidário e também contraditório, de sistemas de objetos e sistemas de ações, não considerados isoladamente, mas como o quadro único no qual a história se dá.” Incorporou em sua tentativa de construção desse conceito, que sempre viu como algo dinâmico, a noção de rede, sendo que o sistema de objetos é a paisagem, cada vez mais artificializada, e o sistema de ações é a sociedade, cada vez mais globalizada. E ambos se materializam no espaço geográfico.

Como resultado dessas críticas ao espaço geográfico como conceito estruturante da proposta curricular do PCNEM (BRASIL, 1999, 2002) e do PCN + (BRASIL, 2002a), as novas Orientações Curriculares para o Ensino Médio (BRASIL, 2006) passaram a propor em seu lugar as categorias de espaço e tempo, junto do conceito de sociedade. A pergunta que fica é: como os professores da escola básica, na busca de compreender as relações entre os homens e destes com a natureza, operacionalizarão espaço e tempo como categorias?

As passagens transcritas acima ilustram alguns dos embates teóricos no campo disciplinar, na geografia acadêmica, e as dificuldades de transposição didática e implantação de reformas curriculares na escola básica. Como foi dito, o currículo, além de expressar subjetividades sociais, molda-as, expõe conflitos epistemológicos, teórico-metodológicos e, muitas vezes, ideológicos.

$\mathrm{Na}$ realidade, críticas e sugestões apontam caminhos e são um passo necessário para encontrá-los. Somente o avanço das pesquisas, a reflexão e o debate poderão defini-los com maior clareza. Uma questão é certa: seja qual for o caminho a ser trilhado, com o advento da revolução informacional, 
a geografia - acadêmica e escolar - também está sendo instada a rever seus conteúdos e, mais do que isso, seu arcabouço teórico-metodológico, para garantir sua capacidade explicativa e, portanto, seu lugar como disciplina relevante na sociedade do conhecimento. Na escola básica, torna-se fundamental a seleção de conteúdos relevantes e contextualizados, o levantamento de informações consistentes, que possam embasar a produção de conhecimentos geográficos, possibilitando aos alunos uma melhor compreensão do acelerado mundo contemporâneo, organizado sob o modo de desenvolvimento informacional e sobre um meio crescentemente técnico-científico-informacional. Entretanto, o fato de a geografia ser uma disciplina multiparadigmática expõe a diversidade de enfoques teórico-metodológicos em seu campo acadêmico e as dificuldades de transposição para a escola básica. Esse fato pode ser uma riqueza, mas também pode se revelar um problema ao enfraquecer sua capacidade explicativa e fragilizá-la perante outras disciplinas.

\section{Considerações finais}

$\mathrm{Na}$ era informacional, enquanto Manuel Castells pensa em economia do conhecimento, sob uma perspectiva economicista, Pierre Lévy pensa em economia do humano, sob uma perspectiva humanista.

Seria um grande avanço se o sistema econômico, em vez de buscar apenas a valorização do capital, a ampliação dos lucros - e nesse caso o homem continuaria sendo visto como meio -, buscasse a valorização do ser humano, o engrandecimento das pessoas, que nesse caso seriam vistas como fim.

Seria muito auspicioso, como defende o economista indiano Amartya Sen, se o desenvolvimento econômico deixasse de ser um fim em si mesmo e passasse a ser um meio para o desenvolvimento humano, a expansão das liberdades reais das pessoas e a realização dos projetos pessoais. Em suas palavras (SEN, 2000, p. 17):

Ver o desenvolvimento como expansão de liberdades substantivas dirige a atenção para os fins que o tornam importante, em vez de restringi-la a alguns dos meios que, inter alia, desempenham um papel relevante no processo.

Considerando o cenário do mundo atual, tudo isso não deixa de ser uma utopia, uma ilusão. Mas sem utopia não nos movemos para frente, sem ilusão não projetamos o futuro e sem projeto morremos como ser humano. E o meio para a realização tanto dos projetos pessoais como coletivos passa necessariamente pela educação, que, portanto, deveria ser a prioridade máxima de todos os governos, especialmente no Brasil. Porém, a educação escolar não pode de maneira nenhuma limitar-se a dar respostas às necessidades do sistema produtivo, embora esse papel não possa ser desprezado, especialmente na sociedade do conhecimento globalizada, na qual a competição por mercados e por empregos é crescente. Portanto, o desafio crucial que se coloca para a escola é compatibilizar a formação do trabalhador-cidadão preparado para o mundo de hoje e da pessoa humana emancipada, no sentido atribuído por Habermas (1993), e livre, como defende Sen (2000). A geografia escolar tem muito a contribuir para isso, especialmente se conseguir trilhar caminhos mais consistentes no processo de explicação do mundo. 


\section{Referências}

ADORNO, T. W. Educação e emancipação. Rio de Janeiro: Paz e Terra, 1995.

APPLE, M. W. Ideologia e currículo. 3. ed. Porto Alegre: Artmed, 2006.

ARENDT, H. Entre o passado e o futuro. São Paulo: Perspectiva, 2005.

AUSUBEL, D. P. Aquisição e retenção de conhecimento: uma perspectiva cognitiva. Lisboa: Plátano, 2003.

BECKER, F. A origem do conhecimento e a aprendizagem escolar. Porto Alegre: Artmed, 2003.

BRASIL. Ministério da Educação. Secretaria de Educação Média e Tecnológica. Parâmetros curriculares nacionais: ensino médio: ciências humanas e suas tecnologias. Brasília: MEC; SEMTEC, 1999.

. Ministério da Educação. Secretaria de Educação Média e Tecnológica. Parâmetros curriculares nacionais: ensino médio. Brasília: MEC; SEMTEC, 2002.

. Ciências humanas e suas tecnologias. Brasília: MEC; SEMTEC, 2002a. (PCN + ensino médio: orientações complementares aos parâmetros curriculares nacionais).

. Secretaria de Educação Básica. Orientações curriculares do ensino médio. Brasília: MEC/SEB, 2004. Disponível em: <http://portal.mec.gov.br>. Acesso em: 21 jun. 2005.

Ciências huma-

nas e suas tecnologias. Brasília: MEC/SEB, 2006. (Orientações curriculares para o ensino médio; v. 3).

CANADÁ. Gouvernement du Québec. Québec Schools on Course: educational policy statement. Québec: Ministère de l’Éducation, 1997.

CASTELLS, M. A sociedade em rede. São Paulo: Paz e Terra, 1999. (A era da informação: economia, sociedade e cultura; v. 1).

DELORS, J. (Org.). Educação: um tesouro a descobrir. Relatório para a UNESCO da Comissão Internacional sobre Educação para o século XXI. 6. ed. São Paulo: Cortez; Brasília, DF: MEC/UNESCO, 2001.

EGAN, K. A mente educada: os males da educação e a ineficiência educacional das escolas. Rio de Janeiro: Bertrand Brasil, 2002.

ESPAÑA. Ministerio de Educación y Ciencia. Secretaría General de Educación. Una educación de calidad para todos y entre todos: propuestas para el debate. Madrid, 2004. Disponível em: <http://www. mec.es>. Acesso em: 21 jun. 2005.

ESPAÑA. Jefatura del Estado. Ley Orgánica 2/2006, de 3 de mayo, de Educación. Boletín Oficial del Estado, Madrid, n. 106, p. 1715817207, 4 mayo 2006. Disponível em: <www. boe.es/g/es>. Acesso em: 2 out. 2008.

GARDNER, H. Estruturas da mente: a teoria das inteligências múltiplas. Porto Alegre: Artes Médicas, 1994.

. Inteligências múltiplas: a teoria na prática. Porto Alegre: Artes Médicas, 1995.

. MI after twenty years. Cambridge: Howardgardner.com, 2006. Disponível em: $<$ www.howardgardner.com/Papers/papers. html>. Acesso em: 12 mar. 2008.

GOODSON, I. F. Currículo: teoria e história. Petrópolis: Vozes, 1995.

HABERMAS, J. Passado como futuro. Tradução Flávio Beno Siebeneichler; entrevistador Michael Haller. Rio de Janeiro: Tempo Brasileiro, 1993. (Coleção Biblioteca Tempo Universitário; n. 94, Série Estudos Alemães). 
HARVEY, D. A condição pós-moderna: uma pesquisa sobre as origens da mudança cultural. 2. ed. São Paulo: Edições Loyola, 1993.

HOBSBAWN, E. J. Nações e nacionalismo desde 1780: programa, mito e realidade. Rio de Janeiro: Paz e Terra, 1990.

JOHNSON, A. G. Dicionário de sociologia: guia prático da linguagem sociológica. Rio de Janeiro: Jorge Zahar, 1997.

KUMAR, K. Da sociedade pós-industrial à pós-moderna: novas teorias sobre o mundo contemporâneo. Rio de Janeiro: Jorge Zahar, 1997.

LACOSTE Y. A geografia: isso serve, em primeiro lugar, para fazer a guerra. Campinas: Papirus, 1988.

LEFEBVRE, H. Lógica formal, lógica dialética. 5. ed. Rio de Janeiro: Civilização Brasileira, 1969.

LÉVY, P. A inteligência coletiva: por uma antropologia do ciberespaço. São Paulo: Edições Loyola, 1998.

LOJKINE, J. A revolução informacional. São Paulo: Cortez, 1995.

MACHADO, N. J. Conhecimento e valor. São Paulo: Moderna, 2004.

Educação: projetos e valores. 3. ed. São Paulo: Escrituras, 2002.

Epistemologia e didática: as concepções de conhecimento e inteligência e a prática docente. 4. ed. São Paulo: Cortez, 2000.

MARINA, J. A. Teoria da inteligência criadora. Lisboa: Caminho, 1995.

MORAES, A. C. R. Geografia: pequena história crítica. 20. ed. São Paulo: Annablume, 2005.
; COSTA, Wanderley Messias da. Geografia crítica: a valorização do espaço. São Paulo: Hucitec, 1987.

PERRENOUD, P. Construir as competências desde a escola. Porto Alegre: Artmed, 1999.

PONTUSCHKA, N. N. A geografia: ensino e pesquisa. In: CARLOS, A. F. A. (Org.). Novos caminhos da geografia. São Paulo: Contexto, 1999.

SANTOS, M. Sociedade e espaço: a formação social como teoria e como método. Boletim Paulista de Geografia, n. 54. Associação dos Geógrafos Brasileiros Seção São Paulo, Jun. 1977.

. Por uma geografia nova. Da crítica da geografia a uma geografia crítica. 2. ed. São Paulo: Hucitec, 1980.

A natureza do espaço. técnica e tempo, razão e emoção. São Paulo: Hucitec, 1996.

SEN, A. Desenvolvimento como liberdade. São Paulo: Companhia das Letras. 2000.

SIMON, I. A revolução digital e a sociedade do conhecimento. Curso ministrado no IME-USP, 1999. Disponível em: <www. ime.usp.br/ is/ddt/mac333>. Acesso: 27 jun. 2005.

SPOSITO, E. S. Geografia e filosofia: contribuição para o ensino do pensamento geográfico. São Paulo: Editora UNESP, 2004.

U.S. Department of Education. Office of the Secretary. Office of Public Affairs. A guide to education and no child left behind. Washington, D.C.: U.S. Department of Education, 2004.

VIGOTSKI, L. S. Pensamento e linguagem. São Paulo: Martins Fontes, 2003. 
VIÑAO, A. La educación comprensiva. Experimento con la utopía... tres años después. In: ALANÍS FALANTES, Leonardo (Coord.). Debate sobre la ESO: luces y sombras de una etapa educativa. Madrid: Universidad Internacional de Andalucía / Akal, 2003.

Enviado em: 10/03/2010

Aceito em: 04/05/2011 